\title{
An investigation of influencer body enhancement and brand endorsement
}

\author{
Sarah Lefebvre \\ slefebvre@murraystate.edu \\ Kelly Cowart \\ University of South Florida, cowartk@usf.edu
}

Follow this and additional works at: https://digitalcommons.murraystate.edu/faculty

Part of the Marketing Commons

\section{(c) (i)}

This work is licensed under a Creative Commons Attribution 4.0 International License.

\section{Recommended Citation}

Lefebvre, S. and Cowart, K. (2022), "An investigation of influencer body enhancement and brand endorsement", Journal of Services Marketing, Vol. 36 No. 1, pp. 59-72. https://doi.org/10.1108/ JSM-12-2020-0509

This Journal Article is brought to you for free and open access by the Faculty Works at Murray State's Digital Commons. It has been accepted for inclusion in Faculty \& Staff Research and Creative Activity by an authorized administrator of Murray State's Digital Commons. For more information, please contact msu.digitalcommons@murraystate.edu. 


\title{
An investigation of influencer body enhancement and brand endorsement
}

\begin{abstract}
Purpose: As the cosmetic surgery industry grows and diversifies, societal beauty standards have shifted to include images of surgically enhanced bodies. With the increased use of influencer marketing, it is important for marketers to understand consumer perceptions of these modified appearances. This research uses the lens of perceived morality to investigate consumer perceptions of cosmetic surgery services and the effect of enhanced body appearance on consumer interest in an endorsed brand. Interpersonal similarity is tested as a boundary condition.
\end{abstract}

Design/Methodology/Approach: A mixed-methods approach was taken with a qualitative study and two online experiments. Participants were recruited through snowball sampling $\left(\mathrm{N}_{\text {Study } 1}=133\right)$ and Amazon Mechanical Turk $\left(\mathrm{N}_{\text {Study } 2}=202 ; \mathrm{N}_{\text {Study } 3}=270\right)$.

Findings: The themes uncovered in the qualitative study revealed that cosmetic surgery services were acceptable when internally motivated but may signal inauthenticity. The findings of Study 2 suggested consumer interest in an endorsed brand was negatively impacted by body enhancement, with perceived morality as the underlying mechanism. Study 3 results demonstrated interpersonal similarity moderated this effect. The indirect effect was significant only for those low in interpersonal similarity.

Originality: This research contributes to the underexplored area of cosmetic surgery services and its role in influencer marketing. The findings extend the literature on consumer attitudes and perceptions towards these services and provides insight into the intersection of body enhancement and morality. The contribution is notable since marketers increasing rely on social media influencers, many of whom have undergone cosmetic surgery services and enhanced their body appearance, to promote their brands.

Keywords: Cosmetic Surgery Services, Social Perceptions, Morality, Influencer Marketing

Paper Type: Research paper 


\section{Introduction}

Cosmetic surgery is defined as elective procedures that focus on enhancing appearance through surgical and medical techniques (American Academy of Cosmetic Surgery, n.d.). The ability to permanently enhance the natural body shape and size through cosmetic surgery has typically been stigmatized, making it taboo to discuss even with friends and family. However, in 2019, more than 18.1 million cosmetic surgery services were performed in the United States (U.S.) alone. Most of these procedures were body, rather than facial, enhancements; breast augmentation and liposuction were the two top surgical procedures. Furthermore, buttock augmentation with fat grafting experienced the largest growth with a 17\% increase from 2018 to 2019 (American Society of Plastic Surgeons, 2020). The surge in cosmetic surgery services raises the question: Has this once unmentionable topic become socially acceptable? This research informs that discussion by examining the normalization of body enhancement by social media influencers and the eventual impact on endorsed brands.

In the 1990s, many cosmetic surgery patients wanted to look like celebrities. In the 2000s, a cultural shift toward reality television created a new category of 'stars' who became models for cosmetic surgery (e.g., the Kardashians). Today, people's desires for an idealized version of themselves are being motivated by social media influencers (SMIs [ISAPS, 2018]), for whom cosmetic surgery is quite common and has played an integral role in establishing these human brands. Human brands refer to individuals whose career, public appearance, and endorsements are carefully controlled to enhance their personal appeal and distinguish them from others (Thomson, 2006). Social media marketing generated \$9.7 billion in 2020 (Statista, 2021) largely as a result of SMIs who brokered brand endorsements with the intent of affecting consumer decision making (Nascimento et al., 2020). Compared to traditional celebrities, consumers feel 
more connected with influencers, creating a sense of interpersonal intimacy and a desire to imitate them (Kowalczyk and Pounders, 2016).

The source credibility model postulates that expertise and trustworthiness create the perceived credibility of a source (Yuan and Lou, 2020). Building on this, researchers have shown that the perceived credibility (Argyris et al., 2021), and trustworthiness (Jin et al., 2019) of SMIs are the most effective traits in promoting an endorsed brand. While trustworthiness and expertise are paramount, the visual, picture-orientated nature of social networking sites, especially Instagram, requires SMIs to create a 'perfect' image to accompany the user generated content and maximize potential returns. This typically entails the correct product placement and most importantly the portrayal of a model-like appearance. However, the final, curated image can contradict the original perceptions of the influencer. In fact, research investigating unenduring appearance alterations (e.g., make-up), finds increased alteration can decrease perceptions of authenticity (Smith et al., 2021) and morality (Samper et al., 2018). With the evolution of the ideal female body and the appearance driven nature of influencer marketing, it is not surprising that influencers may elect cosmetic surgery services to maintain a consistent, enduring brand image. The literature has recognized the importance of influencer characteristics when engaging in influencer marketing (Vrontis et al., 2021). Thus, it is important for marketers to consider how the outcomes of cosmetic surgery services (i.e., body enhancement) are perceived by consumers, and in turn, impact an influencer endorsed brand.

The current research identifies a novel appearance-based cue that affects observers' judgments about a SMI and an endorsed brand. This is the first project, to our knowledge, to examine the influence of cosmetic surgery services on consumer brand interest through the lens of SMI marketing. We examine body enhancement rather than facial aesthetics to determine whether 
influencers with surgically enhanced bodies draw less interest in an endorsed brand than those with natural bodies. Perceived morality is explored as a theoretical underpinning of the observed effect and interpersonal similarity is examined as a boundary condition. We expand the social perception and social media marketing literature, which have recorded predominantly positive creditability associated with influencer marketing (Jin et al., 2019). This research contributes to the services literature by examining the underexplored industry of cosmetic surgery services and enhances the influencer marketing literature by identifying influencer characteristics that may have a negative impact on brand interest.

\section{Literature review}

\subsection{Normalization of body enhancements}

Cosmetic surgery has traditionally been viewed as a service that alters the human body to align with societal ideals of beauty (Negrin, 2002). Yet, in an era dominated by the body positivity movement, where acceptance of all body types is encouraged, cosmetic surgery services are on the rise. Cosmetic surgery has entered mainstream, becoming increasingly popular and socially acceptable (Swami et al., 2011) after decades of condemnation. The change may be due to attitudinal shifts in undergoing cosmetic surgery in response to constant bombardment of idealized images (Negrin, 2002) to choosing surgery as an act of empowerment and renegotiation of identity through one's body (Davis, 1995). This reforming of identity could be construed as a creation of an individual's true self because of the permanency of cosmetic surgery services, rather than a misrepresentation of the self-achieved through unenduring alterations such as cosmetics. Cosmetic surgery provides a unique form of appearance alteration since the outcomes produce a consistent

appearance for the long-term. Furthermore, unlike cosmetics and most forms of unenduring 
appearance enhancement, cosmetic surgery services are performed by someone else (Samper et al., 2018).

Cosmetic surgery fuels a "pathological aversion of the normal" - as more people obtain "surgically created beautiful faces and bodies" natural beauty attributes will be labeled “technologically primitive" while the "ordinary" will be evaluated as "ugly" (Morgan, 2009). This, coupled with repeated exposure to media portrayals of artificial beauty ideals, can lead society to accept, value, and embrace artificial, manufactured representations of beauty as a standard for social comparison. When women find themselves lacking in (internalized and stereotypical) beauty ideals and they compare themselves to idealized images, they are more apt to consider cosmetic surgery (Walker et al., 2019). These societal beauty ideals have transcended from celebrities like Kylie Jenner and Beyoncé Knowles to non-celebrity influencers who use social media for revenue generation. One result has been the proliferation of influencer marketing, which is the employment of influential opinion leaders with many followers on social platforms, to foster positive consumer responses regarding a brand through shared posts which allow the co-creation of brand image (see Lou and Yuan, 2019).

For instance, influencer Jen Selter has 12.3 million Instagram followers and Jailyne Ojeda has 13.3 million Instagram followers. For both influencers, followers are gained mostly due to the women's physical features, recognizable by their low waist to hips/buttocks ratio. This look is commonly identified as a cosmetically enhanced appearance that is achieved by the most popular cosmetic surgery procedures (i.e., breast augmentation, liposuction and buttock augmentation with fat grafting) to form an hourglass figure (i.e., "a full bust and hips with an obvious waist definition" Alexander et al., 2005). As social media influencers communicate through visual media (e.g., photos and videos), the image that they create is critical to their success as brand endorsers. 


\subsection{The power of social media influencers}

Social media influencers at all levels rely on their relationships with followers to obtain brand endorsements. It's important to recognize that SMI marketing is not limited to small brands that are entering the market; large brands such a Vital Proteins and Bang Energy Performance Beverages are examples of brands that use SMI marketing. The relationship between influencers and endorsed brands is important in creating and maintaining the brand image of both parties. From a brand's perspective, influencers amplify the image of the brand and increase consumer adoption of the brand's products (De Veirman et al., 2017). Influencers are successful endorsers because of their ability to connect with their audiences and allow consumers to personally identify with them. Some followers imitate the look and experiences posted by SMIs (Tran and Strutton, 2014). Consumers perceive influencers as 'real' and approachable because they have achieved their 'status' through more organic channels than traditional celebrities (Jin et al., 2019). In addition, the authenticity of an influencer is primarily based on their sharing of daily experiences that help foster a connection with followers (Stefanone et al., 2010). The resulting interpersonal intimacy is accompanied by an increased perception of credibility (Argyris et al., 2020), and trustworthiness (Jin et al., 2019), that have been shown to impact consumer decision making. For instance, young female social media users are likely to follow the advice of influencers because they are deemed more credible than celebrities (Djafarova and Rushworth, 2017). Broadly, influencers who have a strong following, are viewed positively by their audiences, resulting in beneficial outcomes for brands they endorse. We herein question whether the appearance of cosmetic surgical enhancements challenges the source credibility of SMIs.

Certain types of beauty work are used to make judgements about a woman. For instance, increased beauty effort leads to perceptions of immorality because it signals the degree to which 
she is willing to misrepresent her true physical appearance (Samper et al., 2018). If a woman's beauty is unenduring, it can be perceived as superficial, and not a true representation of who she is. To extend this research stream, we investigate whether or not a woman's enduring beauty, if it is achieved by cosmetic surgery, will also impact perceptions of morality and in turn, a consumer's interest in an endorsed brand. Understanding the antecedents of immorality are important in the context of social media influencer marketing, since social perception is critical to foster a connection between the influencer and audience.

\subsection{The morality of cosmetically enhanced influencers}

Extant research in marketing and advertising has shown the character of an endorser impacts the persuasiveness of their message (Ohanian, 1990). Based on the source credibility model, for an endorsement to be successful, the receiver (followers in the case of social media) must perceive the source (influencer) as possessing expertise and trustworthiness (Rifon et al., 2016). Visual aspects of social media postings have been found to influence perceived credibility of influencers. For instance, Argyris et al. (2021) found when influencers showcase their extroversion through visual presentation they are perceived as credible which in turn increased purchase intentions for the target brand. Expertise is established when a source communicates valid assertions (Ohanian, 1990). For an influencer this is usually achieved through text captions in static posts or verbally in story posts. It is not based on the visual presentations (e.g., photos).

Yet, physical appearance acts as an information cue when forming perceptions about an individual (Lowman et al., 2019). For example, attractive individuals are often perceived as extraverts (Borkenau and Liebler, 1992) and heavier individuals are perceived as emotionally expressive and warm (Cowart and Brady, 2014). Further, beauty related qualities have been shown 
to impact perceptions of individuals in promotional tools. Lowered authenticity perceptions arise from observers' default assumption that beauty work is motivated by self-enhancement and serves primarily to conceal appearances. Conversely, self-expression enhances authenticity by leading others to see beauty work as a form of creation rather than concealment. This pattern extends to when people engage in a variety of beauty work transformations but not when beauty work is designed to restore appearances or is framed as connected to the innate self (Smith et al., 2020).

The stereotype content model pioneered by Fiske and colleagues (1998) fostered the development of social perceptions which consist of three dimensions critical to perception formation of individuals: competence, warmth, and morality (Orlowski et al., 2021). Competence is related to perceived ability (Leach et al., 2007), and expertise (Whitehead, 1968). Warmth is represented through sociability and likeability of an individual. Morality is connected to honesty and trustworthiness (Leach et al., 2007). One's perceived morality is often related to their credibility. However, the two are not interchangeable traits. An individual may be moral by displaying honesty and trustworthiness but lack the expertise to be credible.

Research has found that aspects of beauty influence perceptions of morality. Specifically, the more effort an individual is believed to put into their appearance, the less moral the individual is perceived (Samper et al., 2018). Due to their enduring appearance outcomes, cosmetic surgery services are distinct from appearance dimensions such as attractiveness (e.g., Peng et al., 2020), beauty effort (Samper et al., 2018; Smith et al., 2021), and cosmetics (Negrin, 2000). The longterm results of cosmetic surgery create a unique form of appearance alteration that becomes part of an individual's brand image. Since physical appearance acts as an information cue, cosmetic surgery can lead to perceptions of deception by misleading people to believe artificial enhancements are natural (Dubbs et al., 2017). Thus, it is not the expertise, but the perceived 
morality aspect of source credibility that is altered when an influencer presents visual representations that appear cosmetically enhanced. Specifically, we predict a cosmetically enhanced body will lead to perceived immorality of an influencer, which will reduce consumers interest in the endorsed brand. Thus, we hypothesize:

H1: A body that appears enhanced through cosmetic surgery services (vs. unenhanced) will lead to lower interest in an endorsed brand.

H2: The effect of an enhanced body appearance (vs. unenhanced) on interest in a brand will be mediated by perceived morality of the information source (i.e., an influencer).

\subsection{Interpersonal Similarity}

Recent studies examining the characteristics of source credibility have extended the model to include source homophily (see Ismagilova et al., 2020): an individuals' disposition to associate with those who are similar to themselves. Research on interpersonal similarity demonstrates that perceived similarity leads to an increased liking of an individual (Liviatan et al., 2008). Although social media followers do not have in-person interactions with influencers, they can infer similarity by evaluating created content and profile data. Social homophily can also be detected from perceived attributes (preferences, values, beliefs) and demographic characteristics (Lis, 2013). When an influencers content includes values and preferences similar to the follower, perceived homophily will increase (Blanton, 2013). Thus, interpersonal similarity relates to the values and behaviors shared by individuals and is not limited to similarity in appearance or demographics.

The Elaboration Likelihood Model explains that decisions are based on the characteristics of the information source and previous studies have found that homophily influences consumers' behavior (Jalees et al., 2015). If a follower feels a connection with a SMI, the SMI's message is 
more compelling in consumer decision-making in comparison to heterophily sources (Steffes and Burgee, 2009). Consumers who share high levels of homophily, participate in eWOM with each other more, which in turn influences purchase intention (Chu and Kim, 2011). More specifically, Saleem and Ellahi (2017) found that homophily has a significant, positive impact on purchase intention of Facebook users. The ability for homophily to influence consumer behavior makes this an important variable for marketers to study, particularly in the context of social media influencers who rely on fostering a sense of connection with their audience. To enhance this connection and influence, interpersonal similarity can also act as a trust cue that impacts the persuasiveness of an information source (Packard et al., 2016). In the case of a cosmetically enhanced SMI, a sense of homophily is likely to foster a sense of trust, that counteracts the lowered perceptions of authenticity and trustworthiness, resulting from body enhancement, that lead to immorality perceptions.

We predict that in the presence of an influencer with a cosmetically enhanced body, greater perceived interpersonal similarity will attenuate the negative effect of body enhancement on perceived morality. This is because the similarity with the influencer fosters trust which counteracts the deceptive perceptions associated with cosmetic surgery. Stated formally, we hypothesize:

H3: Interpersonal similarity will moderate the effect of enhanced body appearance on brand interest through perceived morality.

We use a mixed-method approach to explore consumer perceptions of cosmetic surgery services and how these perceptions impact influencer endorsed brands. As the current literature on consumer perceptions of cosmetic surgery services is limited, we conducted Study 1 to examine 
these perceptions and ensure alignment with our proposed theoretically based hypotheses. In Study 2, we examine the effect of an enhanced body appearance on interest in influencer endorsed brands, with perceived morality as the underlying mechanism. In Study 3, we replicate our earlier findings and investigate interpersonal similarity as a boundary condition, while ruling out other social perception dimensions in the causation chain.

\section{Research methodology}

\subsection{Study 1}

Using an online qualitative survey, we attempted to gain insight into consumers current perceptions of cosmetic surgery services and the individuals who utilize these services.

\subsubsection{Participants}

Participants were recruited through social media posts by the researchers. Participants were asked to share the survey via social media, email, or text, creating a snowball convenience sample. The social media post indicated opinions were being sought for academic research on beautification products and services. One-hundred and thirty-three individuals completed the survey $(65 \%$ female, avg. age $=32$ years $)$. Demographics for all studies are posted in Table 1.

\subsubsection{Procedure}

Participants were provided with the American Academy of Cosmetic Surgery's definition of cosmetic surgery. To gain insight into consumer perceptions of cosmetic surgical procedures participants were told, "when answering the following questions please consider "cosmetic surgery" to be cosmetic surgical procedures (e.g., breast augmentation, butt lift, rhinoplasty [nose job], liposuction etc.) for physical enhancement". Participants were asked separately about their opinions towards minimally invasive procedures however, in the context of this research we are focused on cosmetic surgery services only. Participants were asked to indicate their overall 
acceptance of cosmetic surgery procedures $(1=$ strongly disapprove, $7=$ strongly approve $[$ see Table 1]), and in an open-ended response format, explain their response in detail. Demographic questions followed.

\section{[INSERT TABLE 1]}

\subsubsection{Results}

To analyze the open-ended responses, a researcher and a research assistant who was unaware of the research question used an iterative phronetic approach to individually analyze the responses (Tracy, 2020). During the analysis process the source credibility model and stereotype content model were referenced while the descriptive text was read in its entirety to create codes that described reoccurring themes within the responses. Through the iterative process the coded data was then grouped into appropriate categories (Strauss and Corbin, 1988). Discrepancies in the coded data were discussed by the two coders and resolved.

The responses were first examined by valence, positive/accepting versus negative/unaccepting, communicated when participants explained their level of acceptance for cosmetic surgery services. In terms of overall valence, responses revealed more positive than negative attitudes (59\% vs. 32\%). Four themes emerged across the responses, (1) emotion and selfperception, (2) motivation for cosmetic surgery, (3) inauthenticity, and (4) acceptable for others.

A number of participants related engaging in cosmetic surgery services to attempting to achieve emotional states such as, "If a person who is really unhappy about their image wants to use cosmetic surgery as a means to be happy with their image, I think that's fine." Related to partaking in cosmetic surgery services for emotional reasons, an association with perception of oneself also emerged. For instance, participants mentioned "confidence" and "self-esteem" when explaining their acceptance level of cosmetic surgery. Participants stated: 
"I think their [sic] are benefits to it, but that there also needs to be work mentally to help with self esteem and self acceptance to balance the surgical and outward work"

"I don't believe cosmetic surgery is a solution to these problems. People need to look within and value themselves for who they are".

This association between emotional self and cosmetic surgery services implies that motivations for participating in these services are likely perceived as psychologically driven to improve oneself.

Participants also indicated they were more accepting of cosmetic surgery services when the goal is self-improvement versus adherence to societal standards or to impress others. For instance, participants indicated they were accepting when individuals undergo procedures for themselves:

"People should have the freedom to pursue cosmetic surgery if it makes them feel happier and more confident. However, no one should pursue cosmetic surgery based solely on the urging of others or solely to improve others' opinions."

"I strongly disagree with individuals who get cosmetic surgery done so they receive approval from others or if they are chasing youth."

Since SMIs are concerned with appearance, followers may easily assume the driver of body enhancement is to achieve an ideal beauty image. This suggests cosmetic surgery services were not undertaken for self-improvement, reducing acceptance of the influencer's actions. Responses also highlighted the perceived inauthenticity of cosmetic surgery and cosmetic surgery participants through the use of words such as "artificially altering appearance", "appear fake", "plastic", "misleading", and "shallow". These descriptors demonstrate that for some individuals, cosmetic surgery services result in an appearance that is not only unnatural, it devalues the body's true, organic form. 
A subcategory of the general responses was the indication of a threshold of acceptability. This was interpreted to mean that at the point cosmetic surgery outcomes becomes blatantly noticeable, it is perceived that an individual has distorted "who they are" through an alteration of their visual appearance. The threshold for acceptance is accompanied by a concern that the person will become addicted to cosmetic surgical procedures. For instance:

"I like all of them but sometimes people go overboard where it's too much."

"I believe that getting cosmetic surgery opens a door that can be hard to close for some, that's why I only approve somewhat."

Responses emphasizing a threshold of acceptance or potential for obsession highlight that body enhancements can have an acceptable level which is likely to be surpassed when the natural appearance of an individual's body shape becomes questionable. Consumers have a more objectionable response when cosmetic surgery results in an appearance where it is suspected, or it is obvious that the appearance could not be achieved naturally. These enhancements were also linked with dishonesty and inauthenticity. Participants stated:

"It's almost lying to other people about your appearance"

"If you know that the procedure makes you look like something that you are not, people will only like you based on the surgery and not for who you really are".

Taken together, this feedback highlights that once body enhancement is noticeable and the appearance is perceived as fake, it alters the perceived character of individuals who partake in cosmetic surgery as inauthentic, which is contradictory to what makes influencers successful. Since the persuasiveness of influencers depends heavily on the ability to transfer their image to endorsed brands, these findings support the prediction that a cosmetically enhanced body appearance will decrease interest in an endorsed brand. Perceptions of the influencer's character may drive this effect. 
Interestingly, some participants who stated they were accepting of cosmetic surgery services explained there are caveats to their acceptance; namely cosmetic surgery is acceptable for others but not something they would do. For instance, participants stated:

"Just because I wouldn't personally want to undergo cosmetic surgical procedures doesn't mean I think others don't have the right to."

"It's not something that I would do but if it works for someone else go for it."

This also suggests that the acceptance communicated by participants may be due to social desirability bias and assimilation to social norms potentially related to the body positivity movement.

\subsubsection{Discussion}

The purpose of this study was to update and clarify current consumer perceptions of cosmetic surgery services and provide support for the development of our theoretically driven predictions. The findings indicate that although participants outwardly accept cosmetic surgery, there is a negative undertone. Specifically, they were accepting only if the motivations are internal. In addition, participants discussed the perceived inauthenticity of enhanced bodies and how they translate into distrust. In other words, they signified that individuals who have cosmetic surgery can be seen as untrustworthy and inauthentic, which are both components of morality.

This insight brings into question the character of individuals who engage in cosmetic surgery and how they are perceived by others. The findings of this study and presented literature provide support for our predictions (i.e., $\mathrm{H} 1$ and $\mathrm{H} 2$ ) that a cosmetically enhanced appearance may impact perceptions of an influencer's moral character, which in turn will negatively impact followers' interest in an endorsed brand.

Further, in support of $\mathrm{H} 3$, the perceived similarity that an individual has with the source will moderate this effect. This is because interpersonal similarity acts as a trust cue, counteracting 
the distrust created from the enhanced body appearance. Specifically, when an individual perceives low interpersonal similarity with the influencer, an enhanced body appearance will lead to perceived immorality of the influencer, whereas the effect will be attenuated when an individual perceives high interpersonal similarity.

\subsection{Study 2}

Study 2 examines the direct effect of body enhancement on interest in an endorsed brand (H1), and the underlying mechanism of perceived morality (H2).

\subsubsection{Participants}

A total of 202 participants ( $50 \%$ female, avg. age $=42$ years) were recruited through MTurk in exchange for fair monetary compensation. Participants were required to be over the age of 18 and to reside in the U.S. Participants were required to have a minimal approval rating of $93 \%$ and have completed at least 500 human intelligence tasks. To enhance data quality, we used CloudResearch to optimize MTurk functions and we solicited CloudResearch approved participants, who had passed attention and engagement measures. In addition, duplicate IP addresses were blocked within each study, preventing participants from completing the study more than once, and across studies, preventing the same participants from completing Study 2 and 3.

The study utilized a between-subjects, single factor design where participants were randomly assigned to one of two experimental conditions (unenhanced vs. enhanced).

\subsubsection{Procedure}

Participants were told they would review a social media post, then answer questions about themselves and their habits. A fictional Instagram post followed, showing a woman on a beach holding a beverage, which was endorsed in the text copy of the post (see Appendix). The woman in the image was a stock image sourced through ShutterStock.com. In the unenhanced condition 
$(\mathrm{n}=102)$, the photo was unaltered, maintaining the woman's natural body shape and characteristics. In the enhanced condition $(n=100)$, the woman's body was enhanced using Adobe Photoshop and a Body Editor app available through Apple iOS. The waist to hip ratio and breast size were manipulated to mimic the body shape created through common body enhancement surgeries and made popular by media influencers. These areas of the body were also selected as breast augmentation, liposuction, and buttock augmentation were the top three cosmetic surgical procedures performed in 2019 (American Society of Plastic Surgeons, 2020). The exaggeration of the waist to hip ratio was used to ensure the enhancement was noticeably unnatural. The manipulation may be perceived as extreme; however, it mirrors body enhancements commonly seen on notable social media influencers (e.g., Jen Selter, and Jailyne Ojeda).

Fifty participants $(52 \%$ female, avg. age $=36$ years $)$ recruited from MTurk completed a pretest of the enhancement manipulation. Participants reviewed either the unenhanced $(n=25)$ or enhanced body $(n=25)$ image and responded to a series of measures. To assess the effectiveness of the manipulation, participants completed a two item, 7-point scale that asked, "The individual in the picture" (1) "has not had cosmetic surgery/has had cosmetic surgery", and (2) "does not have an enhanced figure/does have an enhanced figure" $(r=.90)$. The results of an independent samples t-test found the unenhanced body image $(M=2.40)$ was perceived as being significantly less cosmetically enhanced than the enhanced body image $(\mathrm{M}=5.25 ; t(48)=-8.25, p<.001)$. Thus, the manipulation was as designed.

In the main study, after reviewing the Instagram post, participants were asked to "Consider the brand in the Instagram post" and indicate their interest in the brand using a three item, 7-point scale (e.g., I would not like more information/ I would like more information, $[\alpha=.96]$ ). To measure morality, a four-item, 7-point likert scale established in the literature was used (moral, 
ethical, genuine, sincere; $1=$ not at all, $7=$ very, $[\alpha=.90]$ ) (Samper et al. 2018). To rule out aesthetic appeal of the individual in the Instagram post as an alternative boundary condition for the effect, a five-item measure of aesthetic evaluation was included (e.g., unattractive/attractive, bad appearance/good appearance, $[\alpha=.97]$; Lam and Mukherjee, 2005). Then, to account for potential social desirability bias, four binary questions from the brief social desirability scale were included (e.g., Do you always practice what you preach to others? Would you ever lie to people?); a higher score indicates a tendency for a participant to provide socially desirable responses (Haghighat, 2007; Pittman, 2020). Demographic questions followed.

\subsubsection{Results}

To assess the effect of body enhancement on brand interest, while accounting for individual social desirability bias, an ANCOVA was conducted using SPSS v.27. The results revealed a significant effect of body enhancement on interest in the endorsed brand $(F(1,201)=3.98, p$ $=.047$ ). Specifically, in support of H1, greater interest in the brand was shown when the influencer's body was unenhanced $(M=3.37)$ than enhanced $(M=2.78)$. Social desirability was significant $(F(1,201)=3.98, p=.048)$ as a covariate.

To examine the underlying mechanism of perceived morality, we used the PROCESS macro (Hayes, 2018; model 4) with 10,000 bootstrap samples. The main effect of body enhancement $(0=$ unenhanced, $1=$ enhanced $)$ on perceived morality was significant $(a=-.45, p=$ .017). Perceived morality was positively related to interest in the brand $(b=.93, p<.001)$. Furthermore, while the indirect effect of body enhancement on interest in the brand was significant (effect $=-.42,95 \% \mathrm{CI}$ from -.777 to -.081$)$, the direct effect of body enhancement on interest in the brand became nonsignificant (effect $=-.15,95 \%$ CI from -.593 to .302 ). Social desirability was 
nonsignificant both in influencing perceived morality and interest in the brand $(p>.06)$. Together, these findings provide evidence of full mediation, in support of $\mathrm{H} 2$.

Aesthetic appeal. We used PROCESS model 1 to assess the interaction of perceived aesthetic appeal with body enhancement on interest in the brand. Social desirability bias was included as covariate. The interaction was nonsignificant $(p=.76)$. To rule out the potential interaction of aesthetic appeal and body enhancement on the mediator, perceived morality, a moderated mediation analysis was conducted (PROCESS model 7 [Hayes, 2018]). The interaction on perceived morality was nonsignificant $(p=.70)$, as was the index of moderated mediation (index $=-.045,95 \%$ CI from -266 to .188$)$.

Lastly, subject demographics were included in the analysis but failed to significantly impact the observed results. Thus, gender, ethnicity, and age variables were omitted in the analyses of Study 2 and Study 3.

\section{[INSERT FIGURE 1]}

\subsubsection{Discussion}

Study 2 provides support for our primary hypotheses, wherein an enhanced body received less interest in a brand promoted by a SMI than a body that appeared unenhanced. Additionally, we provide evidence that perceived morality mediated the effect, while finding a lack of support for aesthetic appeal as a moderator.

\subsection{Study 3}

The purpose of Study 3 was to replicate the findings of Study 2, while increasing generalizability within a different product category with a different influencer. We examine interpersonal similarity as a boundary condition (H3) and rule out other social perceptions (competence and warmth) as alternative mechanisms. 


\subsubsection{Participants}

Two-hundred and seventy participants ( $48 \%$ female, avg. age $=42$ years) completed the study through MTurk in exchange for fair monetary compensation. The study was a two factor between-subjects design where body enhancement was manipulated (unenhanced vs. enhanced) and interpersonal similarity was measured.

\subsubsection{Procedure}

Participants followed the procedure from Study 2; however, the woman in the posting and the product were changed to increase generalizability. Following the process in Study 2, in the unenhanced condition $(\mathrm{n}=122)$ the body of the woman in the image was unaltered representing a natural appearance, while in the enhanced condition $(n=123)$ the waist to hip ratio was altered along with the breast size (see Appendix).

Fifty-one participants ( $49 \%$ female, avg. age $=38$ years) recruited from MTurk completed a pretest of the enhancement manipulation. Participants reviewed either the unenhanced $(n=26)$ or enhanced body $(n=25)$ image and responded to the two item manipulation check measures from the Study 2 pretest $(r=.82)$. The results of an independent samples t-test found the unenhanced body image $(\mathrm{M}=3.20)$ was perceived as being significantly less cosmetically enhanced than the enhanced body image $(\mathrm{M}=5.85 ; t(49)=-7.01, p<.001)$. Thus, the manipulation was adopted.

Following the manipulation, participants completed the 3-item dependent measure and 4item mediator measure from Study 2. To rule out alternative dimensions of social perceptions as mechanisms of the effect, established measures of competence ( 4 items, $\alpha=.97$; Johnson et al., 2019), and warmth ( 2 items, $r=.91$, Orlowski et al., 2021) were also included. Then, participants completed an established 3-item interpersonal similarity bipolar scale (not at all similar to me/very 
similar to me; not at all like me/very much like me; nothing in common with me/very much in common with me, $\alpha=.98$; Packard et al., 2016), followed by the 4-item social desirability index. Participants were asked to identify the product endorsed in the Instagram ad as an attention check measure. Demographic questions followed.

\subsubsection{Results}

Two participants failed the attention check measure and were removed, leaving a final sample of 268.

Moderated mediation. To examine the effect of body enhancement on brand interest through perceived morality, conditional on interpersonal similarity, the PROCESS macro (model 7, [Hayes, 2018]) with 10,000 bootstrap samples was use. Social desirability and gender were included as covariates in the model. Participant gender was added as a covariate to account for any differences in interpersonal similarity that may emerge from the influencer in the stimuli being female. The effects of body enhancement $\left(0=\right.$ unenhanced, $1=$ enhanced; $\left.a_{1}=-.821, p<.001\right)$ and interpersonal similarity $\left(a_{2}=.491, p<.001\right)$ on morality were both significant. The interaction of body enhancement and interpersonal similarity on morality was also significant $\left(a_{3}=.179, p=\right.$ .016). Further examination of the interaction finds a Johnson-Neyman critical value of 3.09, such that when individuals rate similarity with the influencer below 3.09, they perceived the influencer with an enhanced body as less moral. In contrast, for individuals who rate their similarity with the influencer above 3.09, body enhancement has no significant effect on perceived morality. In turn, morality has a positive effect on interest in the brand $\left(b_{1}=.842, p<.001\right)$.

The index of moderated mediation was significant, suggesting the effect of body enhancement on interest in the brand through perceived morality is dependent on interpersonal similarity (index $=.151,95 \% \mathrm{CI}$ from .038 to .261 ). Specifically, in support of $\mathrm{H} 3$ the indirect 
effect is significant for those low (-1SD) in interpersonal similarity (effect $=-.541,95 \%$ CI from .847 to -.227 ), while the indirect effect is attenuated for those high (+1SD) in interpersonal similarity. Social desirability was a significant covariate in the first stage of the model but not in the second stage, while gender was a nonsignificant covariate in the first stage, yet significant in the second stage of the model. Complete results can be found in Table 2.

Since only a female influencer was presented in the Instagram stimuli, a separate moderated moderated mediation analysis with participant gender as a moderator was conducted (PROCESS model 11, Hayes 2018) to account for differences in the effect for male and female study participants. The index of moderated moderated mediation was nonsignificant (index $=.012$, 95\% CI from -.226 to .244), inferring the moderated mediation effect was not statistically different for male compared to female participants.

[INSERT TABLE 2 HERE]

\subsubsection{Other social perception dimensions}

To examine other social perception dimensions as potential mechanisms driving the effect of body enhancement on interest in the endorsed brand, a moderated parallel mediation analysis was conducted (PROCESS model 7, [Hayes 2018]), with body enhancement as the independent variable, interest in the brand as the dependent variable, competence, warmth, and morality as the mediators, and interpersonal similarity as the moderator (Figure 2). Social desirability and participant gender were included as covariates.

\section{[INSERT FIGURE 2 HERE]}

The bootstrapping analysis (10,000 samples) showed that body enhancement $\left(a_{11}=-.863\right.$, $p=.001)$ and interpersonal similarity $\left(a_{12}=.410, p<.001\right)$ had significant effects on perceived competence. However, their interaction was not significant $(p>.05)$. In terms of perceived 
warmth, body enhancement $\left(a_{21}=-.735, p=.005\right)$ and interpersonal similarity $\left(a_{22}=.458, p<\right.$ .001) were both significant. Yet, the interaction of body enhancement and interpersonal similarity was not significant $(p>.05)$. The effects of body enhancement and interpersonal similarity on morality remained the same as in the prior moderated mediation analysis. The main effects of body enhancement and interpersonal similarity on morality, along with their interaction, were significant.

Competence and warmth did not significantly influence participants interest in the endorsed brand. Morality had a significant, positive effect on interest in the brand $\left(b_{3}=.675, p<\right.$ .001). The indirect effect of body enhancement on interest in the brand through competence was not significant across levels of interpersonal similarity. The indirect effect of body enhancement on interest in the brand through warmth was also not significant. The indirect effect through morality was significant for participants with low interpersonal similarity (effect $=-.434,95 \% \mathrm{CI}$ from -.737 to -.170$)$, but not for participants with high interpersonal similarity (effect $=-.036,95 \%$ from -.251 to .159). The index of moderated mediation was significant (index $=.121,95 \% \mathrm{CI}$ from .029 to .223$)$. Full results are in Table 3 .

In sum, the moderated parallel mediation analysis implied that warmth and competence did not mediate the interaction of body enhancement and interpersonal similarity on interest in an influencer endorsed brand. However, the social perception dimension of morality significantly mediated the relationship, providing further support for $\mathrm{H} 3$.

\section{[INSERT TABLE 3 HERE]}

\section{Discussion and implications}

\subsection{General discussion}


Cosmetic surgery services are unique in that the 'product' received by the customer is an enduring, appearance alteration created by someone else. Growth in the number of cosmetic surgery services and types of services performed have resulted in a shift in ideal beauty standards. Service marketing scholars should be curious about the effects of and the ensuing implications of this shift on marketing outcomes. Across a qualitative study and two experiments, this research tested three hypotheses regarding the portrayals of SMI with a cosmetically enhanced appearance across two brand categories, adult beverages and fashion accessories. The analysis answers the call for research acknowledging the role of personal appearance in e-commerce (Peng et al., 2020) and on consumer decision making (Samper et al., 2018). The authors also consider traditional notions of beauty in this investigation. We provide empirical support that SMIs with bodies that appear cosmetically enhanced will elicit lower evaluations for an associated brand based on the perceived immorality of the cosmetically enhanced influencer. This effect depends on the level of interpersonal similarity an individual experiences with the influencer.

Overall, this paper enhances our understanding of cosmetic surgery services within the context of influencer marketing. This research finds that cosmetically enhanced bodies may garner attention online but lead to lower subsequent evaluations for endorsed brands. The caveat: surgically enhanced bodies evoke more positive appraisals when the modifications are for internal fulfillment rather than a response to societal pressures. The ability to decipher the SMI's motivation for body enhancements adds a layer of cognitive effort some followers may not be willing to expend. Relatedly, it is important to acknowledge the role of morality in individual and product evaluations on social media. Both the similarities and differences in services marketing practices across media platforms, including when and why different approaches to marketing are practiced, how multiple approaches can be practiced simultaneously and how these practices might be influenced by other 
characteristics are important. As media platforms emerge and mature, marketing theory must also evolve to reflect new developments in practice and research. A better understanding of contemporary services marketing practices and theoretical frameworks should include a spectrum of approaches and not solely transactional or relational paradigms as a conceptual base. This research project attempts to provide a novel perspective to the dynamic sphere of SMI marketing.

\subsection{Theoretical and marketing implications}

The findings of this research make several contributions to the existing literature. First, this research updates the current literature on cosmetic surgery services. Although these services continue to experience tremendous growth, an understanding of consumer attitudes and perceptions of these services remains limited outside of body image and medical literature. Using the source credibility model (Ohanian, 1990) and the stereotype content model (Fiske, 1998) as a foundation, the current research untangles the cognitive complexities that drive perceptions surrounding cosmetic surgery services.

The findings contribute to the social perception literature by identifying a novel aspect of appearance (i.e., body enhancement) that affects observers' judgments about influencers and the associated endorsed brand. While previous research has predominantly focused on the warmth and competence dimensions of social perception, our research focuses on morality, an antecedent of immorality perceptions and the downstream consequences of immorality. The perceived immorality of a SMI had a negative effect on interest in an associated, but unfamiliar brand, thereby extending seminal research on affect-transfer (McGuire, 1985). While previous research found transference of positive emotions between a celebrity endorser and a physical good, we document transference of consumer negative affect for a non-celebrity endorser to an unknown consumer product. Thus, we expand the conceptual frameworks surrounding consumer online 
behavior and non-celebrity endorsers. This contribution further advances the understanding of judgmental heuristics, specifically how physical appearance acts as an information source (Borkenau and Liebler, 1992; Lowman et al., 2019).

Through use of a mixed-methods approach, this research also answers the call for the use of more qualitative research methods in services research (Valtakoski, 2020). Qualitative methods can provide understanding, enhance explanation and interpretation of quantitative data (Tracy, 2020), providing in-depth comprehension. Our use of qualitative data enhanced the understanding of the cognitive complexities of cosmetic surgery services acceptance and provided invaluable support for further investigation.

This study also makes several practical implications for SMIs (i.e., marketing managers). First, influencers should seriously consider how their followers perceive and evaluate their moral character. Successful influencers are astute in making appropriate verbal and posted statements to avoid ostracism in the current cancel culture. They should be equally cautious in presenting their bodies and body augmentation in a manner that does not impair their ability to connect with, or speak to, communities of interest. As mentioned earlier, some followers may not have the cognitive capacity or interest in seeking motivation information although it subconsciously impacts their decision-making. Results of the qualitative study indicate that SMI who undergo body enhancements may benefit from sharing with followers that cosmetic surgeries were undertaken for personal fulfillment and represent their reformed true identity. This may eradicate assumptions of vanity or deceitfulness that can arise. Determining methods to increase positive perceptions of morality and other individual traits should translate to positive evaluations for endorsed products. First impressions and judgments about social traits are formed almost instantaneously (Samper et al., 2018). 
Furthermore, the findings implicitly suggest the cosmetic surgery services industry should leverage advertising appeals that promote personal fulfillment as the motivation for elective surgery rather than the common sexual appeals used by many practitioners. The new information gleaned on public acceptance of cosmetic surgery implies a multiple market approach may work best. For example, a romantic appeal may work for prospective clients hoping to attract (or keep) a mate while an emotional appeal (i.e., feel good about yourself) may work for another consumer segment.

\subsection{Limitations and future research}

There are several limitations of our research that provide opportunities for future investigation. First, we studied cosmetic surgery as it relates to evaluations of female SMIs although males make up a large portion of personal Instagram, Twitter, and Facebook accounts worldwide (Statista, 2020), future research should investigate the role of cosmetic surgeries on evaluations of male influencers. Additionally, the visual stimuli in this research highlighted models ages 25-30. Individuals ages 40-54 comprise the majority of cosmetic procedure patients - $49 \%$ of the total. Since our society is rapidly aging (United Nations, 2019), it is prudent to consider how mature bodies are evaluated on social media. The current findings pertain primarily to U.S. based consumers. Since cultural differences impact consumer behavior, future research should consider the impact of cultural context on evaluations of influencer body enhancements. For instance, idealized appearances vary across cultures and may impact the perceived morality of the source differently based on geographic location and associated cultural norms.

The stimuli used in Studies 2 and 3 exaggerated the waist to hip ratio to a level that ensured the enhancement was noticeably unnatural. Future research should attempt to identify a threshold where body enhancements are less extreme. The availability of photo enhancing applications and 
editing programs is also becoming increasingly prevalent for social media users. Although the use of this type of editing to alter body attributes increases the risk of an inconsistent appearance and brand image on social media, future research should consider the belief that an influencers body enhancement is the result of photo editing or actual alteration through cosmetic surgery services.

With the growing popularity of cosmetic surgery services for appearance enhancement, it is no surprise to see an uptick of influencers who have engaged in cosmetic surgeries to improve body appearance and gain a competitive advantage over the millions of other online influencers that exist. The obvious body enhancements flaunted by online influencers contradicts prior research that finds credibility, especially trustworthiness, to be the foundation of a strong influencer-follower relationship and favorable brand evaluations. When the enhancement results in an appearance that is unnatural, despite desirability or aspirational status, it can signal a lack of honesty. Taken together, an influencer with an enhanced body appearance is likely to be perceived as less moral and thus, gain less interest in the endorsed brand than an influencer with a body that appears unenhanced or natural. These findings contradict the practices of many SMIs and are worth due consideration as online marketing continues to displace traditional channels. An intriguing direction for future research would be a comparative cross-cultural study between Western and non-Western countries to test the hypothesized relationships as it is likely country of origin and culture may impact the findings. 


\section{References}

Alexander, M., Connell, L.J., and Presley, A.B. (2005), "Clothing fit preferences of young female adult consumers", International Journal of Clothing Science and Technology, Vol. 17 No. 1, pp. $52-64$.

American Academy of Cosmetic Surgery. (n.d.), "About cosmetic surgery”, available at: https://www.cosmeticsurgery.org/page/CosmeticSurgery (accessed 9 November 2020).

American Society of Plastic Surgeons (2020), "Plastic Surgery Statistics Report", available at: https://www.plasticsurgery.org/documents/News/Statistics/2019/plastic-surgery-statistics-fullreport-2019.pdf (accessed 10 November 2020).

Argyris, Y.A., Muqaddam, A., and Miller, S. (2021), "The effects of the visual presentation of an influencer's extroversion on perceived credibility and purchase intentions-moderated by personality matching with the audience", Journal of Retailing and Consumer Services, Vol. 59, 102347.

Blanton, H. (2013), "Evaluating the self in the context of another: the three-selves model of social comparison assimilation and contrast", Cognitive Social Psychology, pp. 79-91

Borkenau, O. and Liebler, A. (1992), “Trait inferences: Sources of validity at zero acquaintance”, Journal of Personality and Social Psychology, Vol. 62, pp. 645 - 657.

Chu, S. C., and Kim, Y. (2011), "Determinants of consumer engagement in electronic word-ofmouth (eWOM) in social networking sites", International Journal of Advertising, Vol. 30 No. 1, pp. 47-75.

Cowart, K. O. and Brady, M. K. (2014), "Pleasantly plump: Offsetting negative obesity stereotypes for frontline service employees”, Journal of Retailing, Vol. 90 No. 3, pp. 365-378.

Davis, K. (1995), "Reshaping the female body: The Dilemma of cosmetic surgery", New York: Routledge.

De Veirman, M., Cauberghe, V. and Hudders, L. (2017), "Marketing through Instagram influencers: The impact of number of followers and product divergence on brand attitude", International Journal of Advertising, Vol. 36 No. 5, pp. 798-828.

Djafarova, E. and Rushworth, C. (2017), “Exploring the credibility of online celebrities' Instagram profiles in influencing the purchase decisions of young female users", Computers in Human Behavior, Vol. 68, pp. $1-7$.

Dubbs, S.L., Kelly, A.J., and Barlow, F.K. (2017), "Ravishing rivals: Female intrasexual competition and cosmetic surgery", Oxford Handbooks Online, Oxford University Press.

Fiske, S.T. (1998), “Stereotyping, prejudice, and discrimination”, In D.T. Gilbert, S.T. Fiske, and G. Lindzey (Eds), The handbook of social psychology (4 ${ }^{\text {th }}$ ed., Vol. 2), New York: McGraw-Hill, pp. $357-411$. 
Haghighat, R. (2007), "The development of the brief social desirability scale (BSDS)", Europe's Journal of Psychology, Vol. 3 No.4

Hayes, A. (2018), Introduction to mediation, moderation, and conditional process analysis: A regression-based approach ( $2^{\text {nd }}$ ed.), New York, NY: The Guilford Press.

Ismagilova, E., Slade, E., Rana, N.P., and Dwivedi, Y.K. (2020), "The effect of characteristics of source credibility on consumer behavior: A meta-analysis", Journal of Retailing and Consumer Behavior, Vol. 53, pp. 101736.

ISAPS (2018), "How social media and plastic surgery go hand in hand", available at: https://www.isaps.org/blog/how-social-media-and-plastic-surgery-go-hand-in-hand/ (accessed 27 April 2021).

Jalees, T., Tariq, H., Zaman, S.I., and Kazmi, S.H.A., (2015), "Social media in virtual marketing: Antecedents to electronic word of mouth communication", Marketing Forces, Vol. 10 No. 1, pp. $15-32$.

Jin, S.V., Muqaddam, A. and Ryu, E. (2019), "Instafamous and social media influencer marketing”, Marketing Intelligence \& Planning, Vol. 37 No. 5, pp. 567-579.

Johnson, Z. S., Mao, H., Lefebvre, S. and Ganesh, J. (2019), "Good guys can finish first: How brand reputation affects extension evaluations", Journal of Consumer Psychology, Vol. 29 No. 4, pp. 565-583.

Kowalczyk, C. M., and Pounders, K. R. (2016), "Transforming celebrities through social media: the role of authenticity and emotional attachment", Journal of Product \& Brand Management, Vol. 25 No. 4, pp. $345-356$.

Lam, S.Y. and Mukherjee, A. (2005), "The effects of merchandise coordination and juxtaposition on consumers' product evaluation and purchase intention in store-based retailing", Journal of Retailing, Vol. 81 No. 3, pp. 231-250.

Leach, C. W., Ellemers, N., and Barreto, M. (2007), "Group virtue: The importance of morality (vs. competence and sociability) in the positive evaluation of in-groups", Journal of Personality and Social Psychology, Vol. 93 No. 2, pp. 234 - 249.

Lis, B. (2013), "In eWOM we trust", Business \& Information Systems Engineering, Vol. 5 No. 3 pp. $129-140$.

Liviatan, I., Trope, Y., and Liberman, N. (2008), "Interpersonal similarity as a social distance dimension: Implications for perception of others' actions", Journal of Experimental Social Psychology, Vol. 44 No. 5, pp. 1256-1269.

Lou, C. and Yuan, S. (2019), "Influencer marketing: How message value and credibility affect consumer trust of branded content on social media", Journal of Interactive Advertising, Vol. 19 No. 1, pp. 58-73. 
Lowman, G.H., Harms, P.D., and Mills, M.J. (2019), “The influence of job candidates' physical appearance on interview evaluations", Journal of Personnel Psychology, Vol. 18 No. 2, pp. 55 70.

McGuire, W. J. (1985), “Attitudes and attitude change,” Lindzey, G.E. and Aronson, E.E. (Ed.s), Handbook of Social Psychology, Vol. 2, Random House, New York, NY, pp. 233-346.

Morgan, K. P. (2009), “Women and the knife: Cosmetic surgery and the colonization of women's bodies", Cosmetic Surgery: A Feminist Primer, 49-77.

Nascimento, T. C. D., Campos, R. D., and Suarez, M. (2020), "Experimenting, partnering and bonding: a framework for the digital influencer-brand endorsement relationship", Journal of Marketing Management, Vol. 36 No. 11-12, pp. 1009-1030.

Negrin, L. (2000), "Cosmetics and the female body: A critical appraisal of poststructuralist theories of masquerade", European Journal of Cultural Studies, Vol. 3 No. 1, pp. $83-101$.

Negrin, L. (2002), “Cosmetic surgery and the eclipse of identity”, Body \& Society, Vol. 8 No. 4, pp. $21-42$.

Ohanian, R. (1990), "Construction and validation of a scale to measure celebrity endorsers' perceived expertise, trustworthiness, and attractiveness", Journal of Advertising, Vol. 19 No. 3, pp. 39-52.

Orlowski, M., Bufquin, D., and Nalley, M. E. (2021), "The influence of social perceptions on restaurant employee work engagement and extra-role customer service behavior: A moderated mediation model”, Cornell Hospitality Quarterly, Vol. 62 No. 2, pp. 261-275.

Packard, G., Gershoff, A.D., and Wooten, D.B. (2016), "When boastful word of mouth helps versus hurts social perceptions and persuasion", Journal of Consumer Research, Vol. 43 No. 1, pp. 26-43.

Peng, L., Cui, G., Chung, Y., and Zheng, W. (2020), “The faces of success: Beauty and ugliness premiums in e-commerce platforms", Journal of Marketing, Vol. 84 No. 4, pp. 67-85.

Pittman, M. (2020), "Accountability moderates the effects of egoistic and altruistic appeals in prosocial messages", Journal of Consumer Marketing, Vol. 37 No. 7, pp. 807-820.

Rifon, N.J., Jiang, M., and Kim, S. (2016), "Don't hate me because I am beautiful: Identifying the relative influence of celebrity attractiveness and character traits on credibility", Advances in Advertising Research (Vol. VI) Springer Gabler, Wiesbaden, pp. 125-134.

Samper, A., Yang, L.W. and Daniels, M.E. (2018), "Beauty, effort, and misrepresentation: How beauty work affects judgments of moral character and consumer preferences", Journal of Consumer Research, Vol. 45 No. 1, pp. 126-147.

Saleem, A., and Ellahi, A. (2017), "Influence of electronic word of mouth on purchase intention of fashion products in social networking websites", Pakistan Journal of Commerce and Social Sciences, Vol. 11 No. 2, pp. 597-622. 
Smith, R.K., Vandellen, M.R., and Ton, L.A.N. (2021), "Makeup who you are: Self-expression enhances the perceived authenticity and public promotion of beauty work", Journal of Consumer Research, https://doi.org/10.1093/jcr/ucaa066

Statista (2020), "Instagram accounts with the most followers worldwide", available at: https://www.statista.com/statistics/421169/most-followers-instagram/ (accessed December 2 2020).

Statista (2021), "Influencer marketing market size worldwide from 2016 to 2021", available at: https://www.statista.com/statistics/1092819/global-influencer-market-size/ (accessed March 15 2021).

Steffes, E.M., Burgee, L.E. (2009), "Social ties and online word of mouth", Internet Research, Vol. 19 No. 1, pp. 42-59.

Stefanone, M.A., Lackaff, D., and Rosen, D. (2010). "The relationship between traditional mass media and "social media": Reality television as a model for social network site behavior", Journal of Broadcasting \& Electronic Media, Vol. 54 No. 3, pp. 508-525.

Strauss, A.L. and Corbin, J. (1988), Basics of Qualitative Research, Sage Publications, Thousand Oaks, CA.

Swami, V., Campana, A.N.N.B., Ferreira, L., Barrett, S., Harris, A.S., and Tavares, M.D.C.G.C. (2011), "The acceptance of cosmetic surgery scale: Initial examination of its factor structure and correlates among Brazilian adults", Body Image, Vol. 8 No. 2, pp. 179-185.

Tran, G.A. and Strutton, D. (2014), "Has reality television come of age as a promotional platform? Modeling the endorsement effectiveness of celebreality and reality stars", Psychology \& Marketing, Vol. 31 No. 4. Pp. 294-305.

Thomson, M. (2006), "Human brands: Investigating antecedents to consumers' strong attachments to celebrities," Journal of Marketing, Vol. 70 No. 3, pp. 104-19.

Tracy, S. J. (2020), Qualitative research methods: Collective evidence, crafting analysis, communicating impact, $2^{\text {nd }}$ ed. Wiley \& Sons Ltd, Hoboken, NJ.

Tran, G. A., and Strutton, D. (2014), "Has reality television come of age as a promotional platform? Modeling the endorsement effectiveness of celebreality and reality stars", Psychology \& Marketing, Vol. 31 No. 4, pp. 294-305.

United Nations. (2019), "World population ageing", available at:

https://www.un.org/en/development/desa/population/publications/pdf/ageing/WorldPopulationA geing2019-Highlights.pdf (accessed 8 December 2020)

Valtakoski, A. (2020), "The evolution and impact of qualitative research in Journal of Services Marketing”, Journal of Services Marketing, Vol. 34 No. 1, pp. 8 - 23. 
Vrontis, D., Makrides, A., Christofi, M., and Thrassou, A. (2021), "Social media influencer marketing: A systematic review, integrative framework, and future research agenda", International Journal of Consumer Studies, https://doi.org/10.1111/ijcs.12647

Walker, C. E., Krumhuber, E. G., Dayan, S., and Furnham, A. (2019), "Effects of social media use on desire for cosmetic surgery among young women”, Current Psychology, pp. 1-10.

Whitehead Jr, J. L. (1968), "Factors of source credibility”, Quarterly Journal of Speech, Vol. 54 No. 1, pp. 59-63.

Yuan, S., and Lou, C. (2020). "How social media influencers foster relationships with followers: The roles of source credibility and fairness in parasocial relationship and product interest.

Journal of Interactive Advertising, Vol. 20 No. 2, pp. 133-147. 


\section{Appendix}

\section{Study 2 Stimuli}

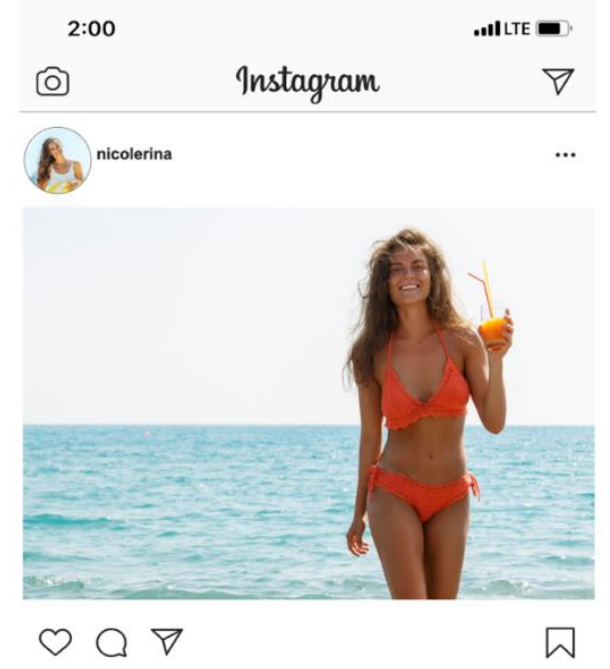

nicolerina Two of my favorite things colliding ... the beach and

@CodiakCocktails, my favorite ready to drink cocktails. These delicious

cocktails come premixed and just need a little ice to keep them cool on

those hot days. Check out the variety of flavor options at the link in bio.

\#codiakcocktails \#readytodrink \#beachlife \#premixedbevs \#delicious

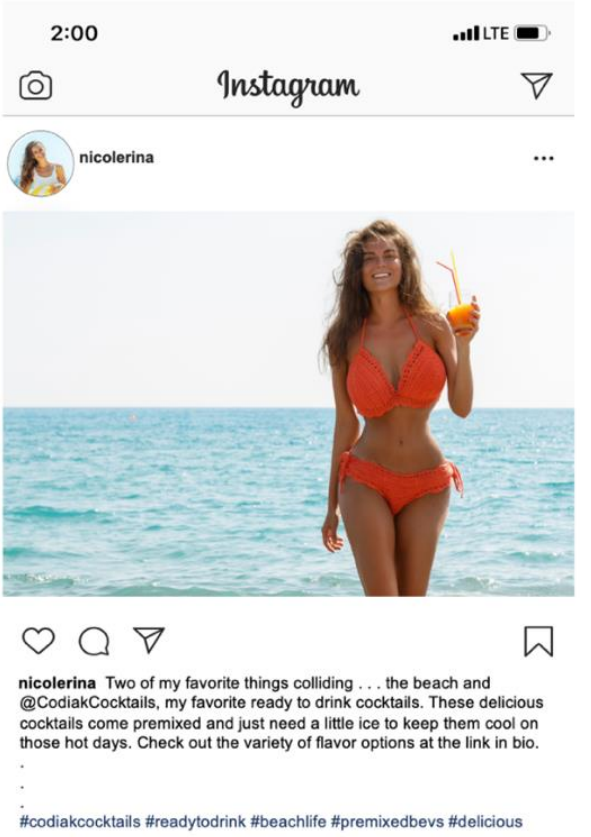

\section{Study 3 Stimuli}

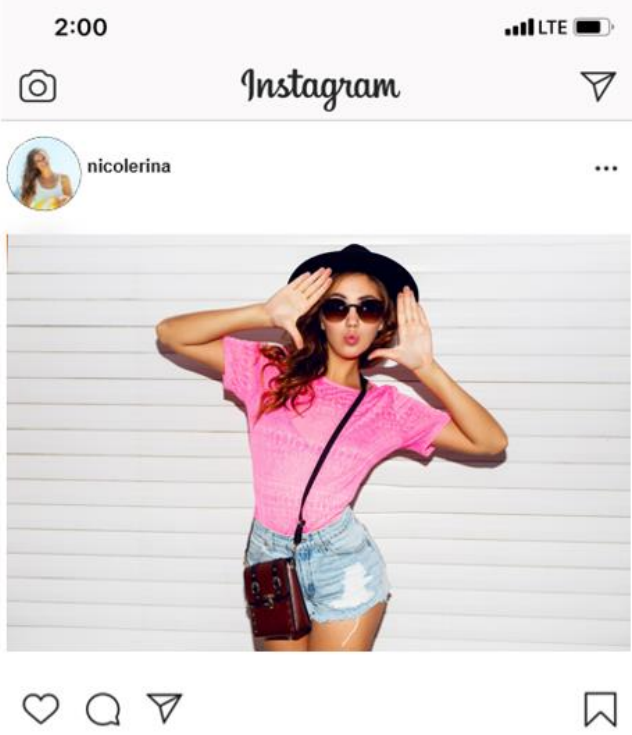

nicolerina We only get one set of eyes, that's why I love @shades my favorite eyewear. They keep my eyes protected and me looking stylish. Check out their frames for men and women. Link in bio.
2:00

.IILTE
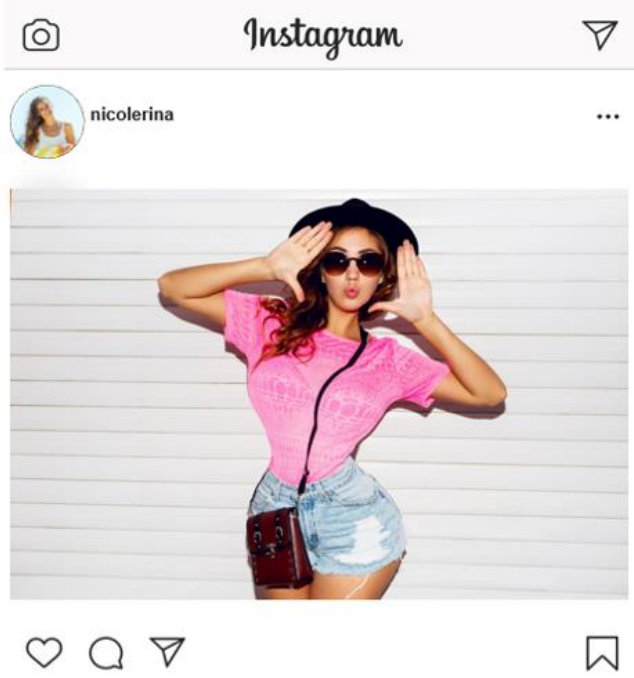

nicolerina We only get one set of eyes, that's why I love @shades my favorite eyewear. They keep my eyes protected and me looking stylish. Check out their frames for men and women. Link in bio.

Note: The extremity of the waist to hip ratio was used to ensure the enhancement was noticeably unnatural. 